\title{
Polymyalgia rheumatica and cancer risk: the importance of the diagnostic set
}

\author{
Ciro Manzo' \\ Maria Natale ${ }^{2}$ \\ 'Department of Geriatric and Internal \\ Medicine, ${ }^{2}$ Geriatric Rheumatologic \\ Outpatient Clinic, Hospital "Mariano \\ Lauro," Sant'Agnello, Naples, Italy
}

This article was published in the following Dove Press journal:

Open Access Rheumatology: Research and Reviews

17 October 2016

Number of times this article has been viewed

Correspondence: Ciro Manzo

Hospital "Mariano Lauro", viale dei Pini I, Sant'Agnello 80065, Naples, Italy

Tel +3908 I533 I465

Email cirmanzo@libero.it
Abstract: In the last few years, the relationship between polymyalgia rheumatica (PMR) and cancer has been considered with very different conclusions. In particular, in 2010, Ji et al examined the overall and specific cancer risks among Swedish subjects following hospitalization for PMR and giant cell arteritis and noted that the risk of cancer was highest in the first year after hospitalization (of 3941 total cancer diagnoses, 783 [19.1\%] were in the first year). In 2013, Muller et al, using data from General Practice Research Database, highlighted that elderly patients with a PMR diagnosis were significantly more likely to receive a cancer diagnosis in the year after PMR diagnosis (313/667 cancer cases [69\%]). In a series of 200 patients with PMR consecutively observed in our geriatric rheumatologic outpatient clinic from 2004 to 2014, we have observed 51 cancer cases; five of these were observed in the first year after diagnosis of PMR (percentage equal to $9.8 \%$ ). In our article, we point out the importance of the diagnostic set. PMR is a disease that can be managed in a rheumatologic outpatient clinic without patients' hospitalization. On the other hand, hospitalization of the elderly with PMR is useful when there are grounds for suspicion for a paraneoplastic syndrome, and this represents per se an important inclusion bias. The studies from institutional databases such as those of Ji et al and Muller et al have a very large series but diagnoses of the various diseases are based on coding and not always confirmed by individual medical record review. On the other hand, studies based on cohorts followed by single rheumatologic outpatient clinics can have much smaller data but have a higher diagnostic accuracy, because all patients are visited by rheumatologists and data are usually more accurate. The specificity of geriatric rheumatologic outpatient clinics with respect to elderly patients and to disease with an outpatient management (such as PMR) is often underestimated. In the health care organization of the geographic area that belongs to the hospital "Mariano Lauro", the majority of patients for whom the general practitioner suspects a PMR are visited by a rheumatologist, as a consequence of an active collaboration between the general practitioner and the rheumatologist and thanks to the very short (5-7 days on average) waiting lists. In our cohort, diagnosis of PMR must be confirmed at least by a second rheumatologist. No change in the initial diagnosis was observed in any of our patients with PMR over the years and even after being examined by other colleagues from different centers. The repercussions of cancer risk in the elderly with PMR on health policies are easily understandable, and therefore the detection of all potential bias is mandatory. Data from other rheumatologic outpatient clinics are necessary. Keywords: polymyalgia rheumatica, cancer risk, paraneoplastic phenomenon, methodology

\section{Introduction}

Polymyalgia rheumatica (PMR) represents the most frequent inflammatory rheumatic disease in the elderly. ${ }^{1,2}$ In patients with PMR, the association of some constitutional signs (fatigue, general malaise, fever, anorexia, or hyporexia) with highly elevated inflammatory 
markers can be a diagnostic challenge with cancer. On the other hand, PMR can represent a paraneoplastic syndrome. ${ }^{3}$

\section{Aim}

To evaluate the relationship between PMR and cancer.

\section{Materials and methods}

We performed a systematic electronic search of Medline and PubMed for evaluation of the relationship between cancer and PMR and present the more significant data. Some personal contributions were also considered.

Diagnosis of PMR was made using the criteria proposed in 1982 by Chuang et $\mathrm{al}^{4}$ and was confirmed at least by a second rheumatologist.

\section{Results}

In recent years, few studies have been published regarding the relationship between PMR and cancer. In 2010, Ji et $\mathrm{al}^{5}$ examined the overall and specific cancer risks among Swedish subjects following hospitalization for PMR and giant cell arteritis (GCA) and noted that the risk of cancer was highest in the first year after hospitalization. In particular, of 3941 total cancer diagnoses, $783(19.1 \%)$ were in the first year. This study utilized the Swedish Hospital Discharge Register. ${ }^{5}$ In 2013, Muller et al $^{6}$ using data from General Practice Research Database (GPRD) highlighted that elderly patients with a PMR diagnosis were significantly more likely to receive a cancer diagnosis in the year after PMR diagnosis (313/667 cases, 69\%). GPRD contains the electronic medical records of patients registered with contributing general practices in England and Wales. Diagnosis of PMR was supported by the requirement that patients had received at least two prescriptions for corticosteroids following diagnosis; however, no data regarding response to treatment were available. ${ }^{6}$ In 2014, Ungprasert et $\mathrm{al}^{7}$ published a systematic review including six studies with pooled statistical analysis revealing a $14 \%$ excess risk of malignancy in patients with GCA/ PMR. The risk of malignancy appeared to be higher in the first 6-12 months after diagnosis. However, when sensitivity analysis was performed excluding one of the six studies due to potential selection bias, the pooled risk ratio decreased to $8 \%$ and did not achieve statistical significance. ${ }^{7}$ In a series of 200 PMR patients consecutively observed in our geriatric rheumatologic outpatient clinic from 2004 to 2014, we have observed 51 cancer cases (Table 1).

The majority of malignancy was diagnosed after $>5$ years from initial diagnosis of PMR. The incidence rate was not different from that of a homogeneous non-PMR population. Only five of these (prostate cancer, vesical cancer, multiple
Table I Cancer in our cohort of PMR patients.

\begin{tabular}{|c|c|c|}
\hline Malignancy site & Number & $\begin{array}{l}\text { In the first year after } \\
\text { diagnosis of PMR }\end{array}$ \\
\hline Any malignancy & 51 & $5 / 51$ \\
\hline Solid & $40 / 51$ & 5 \\
\hline Hematologic & ||$/ 5 \mid$ & 0 \\
\hline Head/neck & 0 & 0 \\
\hline Gastric & 3 & 1 \\
\hline Pancreatic & 5 & 0 \\
\hline Liver & 4 & 0 \\
\hline Colon/rectal & 3 & 0 \\
\hline Other digestive & 1 & 0 \\
\hline Lung & 7 & 1 \\
\hline Other thorax & 0 & 0 \\
\hline Bone & 0 & 0 \\
\hline Soft tissue & 0 & 0 \\
\hline Skin & 3 & 0 \\
\hline Breast (female only) & 4 & 0 \\
\hline Ovary & 2 & 0 \\
\hline Other gynecologic & 1 & 0 \\
\hline Prostate & & 1 \\
\hline Kidney & 1 & 0 \\
\hline Bladder & 3 & 1 \\
\hline Other genitourinary & 0 & 0 \\
\hline Central nervous system & 2 & 0 \\
\hline Lymphoma & 8 & 0 \\
\hline Leukemia & 3 & 0 \\
\hline Multiple myeloma & 1 & 1 \\
\hline Other types & 0 & 0 \\
\hline
\end{tabular}

myeloma, gastric neuroendocrine gastrin-secreting tumor, and adenocarcinoma of the lung, highlighted in bold in Table 1) were observed in the first year after diagnosis of PMR with a percentage equal to $9.8 \%$. Three of these had a remitting seronegative symmetrical synovitis with pitting edema (RS3PE syndrome) as part of the PMR clinical picture. ${ }^{8}$ Our series does not include the elderly with GCA. GCA has per se a neoplastic risk. The very low percentage of cancer diagnosed in our cohort during the first year after the diagnosis of PMR compared to the much higher percentages observed in the two cited studies $(9.8 \%$ vs $19.1 \%$ and vs $69 \%$, respectively) highlights the diagnostic set. ${ }^{9}$

\section{Discussion}

PMR is a disease that can be managed in a rheumatologic outpatient clinic without patients' hospitalization, even if some conditions must be considered in differential diagnosis. The increased accuracy of a geriatric rheumatologic outpatient clinic compared to that of a non-dedicated one has been already highlighted. ${ }^{10}$ Furthermore, the time for diagnosis of PMR is greater if these patients are visited by a general practitioner and more frequent is their hospitalization. ${ }^{11}$ 
This time increases in the territories where the cooperation between general practitioners and rheumatologists is poor and the waiting lists are long. On the other hand, the hospitalization of the elderly with PMR is useful when there are elements suspicious of a paraneoplastic syndrome. Lack of efficacy of glucocorticoid therapy must be considered a strong warning in this direction; a dramatic response to lowdose corticosteroid treatment is characteristic (it represents an important diagnostic criterion for PMR), but in some patients it is necessary to change the glucocorticoid initially used with a different one at equivalent dosage to obtain and/ or regain an effective response.

The studies from institutional databases such as those of Ji et al and Muller et al have a very large series but diagnoses of the various diseases are based on coding and not always confirmed by individual medical record review. On the other hand, studies based on cohorts followed by rheumatologic outpatient clinics can have much less data but a higher diagnostic accuracy, because all patients are visited by rheumatologists and the available data are more accurate. In particular, in the health care organization of the geographic area that belongs to the hospital "Mariano Lauro", the majority of patients for whom the general practitioner suspects a PMR are visited by a rheumatologist, as a consequence of an active collaboration between the general practitioner and the rheumatologist and thanks to the very short (5-7 days on average) waiting lists.

In the elderly patients, the importance of a geriatric rheumatologic outpatient clinic as a reference territorial center is very high. $^{2}$ Most of the time, hospitalization can be useful when we suspect a tumor and this can create an important bias in the selection of the population examined.

Diagnostic criteria by Chuang et $\mathrm{al}^{4}$ have documented a considerable sensitivity and specificity. Furthermore, in our case series, the diagnostic confirmation by a second rheumatologist significantly reduced the risk of inclusion bias. No change in the initial diagnosis was observed in any of our patients with PMR over the years and even after being examined by other colleagues from different centers. The criteria proposed in 2013 by the European League Against Rheumatic diseases (EULAR)/American College of Rheumatology (ACR) collaborative group were not considered since most of our patients were visited before $2013 .{ }^{12}$

\section{Conclusion}

In our experience, PMR is not a paraneoplastic phenomenon. Our data highlighted the importance of the diagnostic set (territorial outpatient clinics vs institutional database). The repercussions of cancer risk in the elderly with PMR on health policies are easily understandable, and therefore the detection of all potential bias is mandatory. Data from other geriatric rheumatologic outpatient clinics are needed.

\section{Disclosure}

The authors report no conflicts of interest in this work.

\section{References}

1. Rooney PJ, Rooney J, Balint G, Balint P. Polymyalgia rheumatica: 125 years of epidemiological progress? Scott Med J. 2015;60(1):50-57.

2. Manzo C, Balduccelli M, Cappiello F, et al. Epidemiology of polymyalgia rheumatica in the Massa Lubrense town. Trends Med. 2009;9(2): $101-105$.

3. Manger B, Schett G. Paraneoplastic syndromes in rheumatology. Nat Rev Rheumatol. 2014;10(11):662-670.

4. Chuang TY, Hunder GG, Ilstrup DM, Kurland LT. Polymyalgia rheumatica: a 10-year epidemiologic and clinical study. Ann Intern Med. 1982;97(5):672-680.

5. Ji J, Liu X, Sundquist K, Sundquist J, Hemminki K. Cancer risk in patients hospitalized with polymyalgia rheumatica and giant cell arteritis: a follow-up study in Sweden. Rheumatology. 2010;49(6):1158-1163.

6. Muller S, Hider SL, Belcher J, Helliwell T, Malle CD. Is cancer associated with polymyalgia rheumatica? A cohort study in the General Practice Research Database. Ann Rheum Dis. 2014;73(10):1769-1773.

7. Ungprasert P, Sanguankeo A, Upala S, Knight E. Risk of malignancy in patient with giant cell arteritis and polymyalgia rheumatica: a systematic review and meta-analysis. Semin Arthritis Rheum. 2014;44(3):366-370

8. Manzo C, Natale M. RS3PE syndrome in polymyalgia rheumatic: a neoplastic marker? Geriatrics. In press, 2016.

9. Manzo C. Cancerogenesis and polymyalgia rheumatica. J Carcinog Mutagen. 2016; 7(3):268

10. van Lankveld W, Frassen M, Stenger A. Gerontorheumatology: the challenge to meet health-care demands for the elderly with musculoskeletal conditions. Rheumatology (Oxford). 2005;44(4):419-422.

11. Manzo C, Natale M, Cappiello F. Quanti anziani con Polimialgia Reumatica passano sotto gli occhi del medico del territorio? Ger Extraosp 2008; VI(4):12-15.

12. Camellino D, Cimmino MA. Are the new ACR/EULAR Criteria the ultimate answer for Polymyalgia Rheumatica classification? J Rheumatol. 2016;43(5):836-838.
Open Access Rheumatology: Research and Reviews

\section{Publish your work in this journal}

Open Access Rheumatology: Research and Reviews is an international, peerreviewed, open access journal publishing original research, reports, editorials, reviews and commentaries on all aspects of clinical and experimental rheumatology in the clinic and laboratory including the following topics: Pathology, pathophysiology of rheumatological diseases; Investigation, treatment and

\section{Dovepress}

management of rheumatological diseases; Clinical trials and novel pharmacologi$\mathrm{cal}$ approaches for the treatment of rheumatological disorders. The manuscript management system is completely online and includes a very quick and fair peer-review system, which is all easy to use. Visit http://www.dovepress.com testimonials.php to read real quotes from published authors. 